\title{
Towards A Shared Public Electronic Services Framework
}

\author{
Amr Ali-Eldin \\ Computer and Control Systems Department, \\ Faculty of Engineering, Mansoura University, \\ Mansoura, Egypt
}

\begin{abstract}
E-Government is an urgent topic for developing countries. In Egypt and after the latest political, societal and economic changes over the last three years, it is becoming a critical issue for economic and sustainable development. In this paper, we enunciate the need for a shared public services framework for e-government in Egypt. Furthermore, we discuss the different aspects that need to be considered by such a framework.
\end{abstract}

\section{General Terms}

Management, Design, Experimentation, Human Factors, Standardization.

\section{Keywords}

Public electronic services, eGovernment, Enterprise Information Systems Architecture, Process Modelling.

\section{INTRODUCTION}

Electronic Government, or eGovernment, is a growing field of practice and research all over the world [1-6]. Information and Communication Technology (ICT) has impacted every government, and there is a real need for services that match citizens and business needs [7]. The challenge for governments in meeting such demands is to achieve integration between front-office services delivery and backoffice to effectively connect citizens to government services [8]. E-Government is multidisciplinary and consists of several domains of research and implementations as e-Democracy, eParticipation, e-Administration, e-Health, and e-Justice [6, 9].

E-government in Egypt is lagging behind other countries in the region [10]. Although e-government is becoming an urgent topic in Egypt, there is still a lot to be done on the level of inter-organisational processes models and the way services are offered to citizens and to private companies. The Egyptian government is focused on bringing innovations in the way things are done in the different Egyptian organisations; many things are expected to improve after the last political changes. E-government in Egypt is still in its infancy, and opens up a lot of development possibilities in the coming future. The currently implemented eGovernmental portal in Egypt offers electronic services in the form of one-stop-shop [10, 11]. It offers a number of electronic services to citizens from the government such as instructions on issuing official documents at a number of states or what they call "governorate". Nevertheless, not all services have been published on the portal and are still under construction.

Additionally, and to the best of the author's knowledge, there is quite limited integration with other agencies on the level of information technology infrastructure. As a consequence, not all the published electronic services offer a complete end-to- end service to the citizens but rather instructions or application and request forms. Further, it has few service catalogues offered as a whole to the citizens and not really adapted to their needs.

In this paper, attention is given to defining the main components needed to provide a shared public electronic services framework that is adapted to the Egyptian Context. Innovation and integration are needed at all levels; organisational, managerial and ICT to allow for a time effective delivery of electronic services to citizens. Besides, electronic services should be oriented to citizens and businesses rather than being governmentally-oriented. This work focuses on the ICT part with the awareness of the impact of some social, organisational and managerial features that characterises the Egyptian Context.

The rest of the paper is organised as follows: in the next section we discuss the motivation for doing this research and the research objectives. Then, in section 3 , we introduce the proposed framework. In section 4 , we discuss related work. Finally we conclude the paper in section 5 .

\section{RESEARCH OBJECTIVES}

This work is a direct response to the needs of Egypt and the call for development raised by Egyptian scholars. We expect that this work will pave the way for sustainable development in the eGovernment enterprise architecture of Egypt and will allow for further innovations in the Information and Communication Technology (ICT) industry.

In this work, we focus on bringing innovative ways of the provisioning of public services by the Municipalities of Egypt. Target groups in this research are the municipalities and their agencies. In addition, this work will improve the way services are modelled and executed. It will reduce the work load by the introduction of automated workflows and by opening new channels to receive applications from citizens and businesses. Most of the work will be done automatically in the back-end systems. The employee will need only to choose the procedure and with a click-button or an event trigger, the whole process lifecycle will be executed without more involvement from the citizen side. The proposed electronic services framework will provide adapted content and services to the citizens and businesses. As a consequence, the municipalities will have more capacity to make effective use of their resources and working hours to serve the citizens and businesses.

To the best of the author's knowledge, there is not much done in Egypt in the context of integrated IT infrastructure using common services and platforms. Most agencies tend to use tightly-coupled and old-fashioned mechanisms that use custom-built database interfaces. This approach makes it quite complex for these systems to evolve and change in the future to meet new demands. Our proposed electronic services 
framework however will be using latest technology standards such as service-oriented architecture technology (as will be mentioned later) and best practices in building enterprise architecture frameworks such as the Open Group Architecture Framework (TOGAF) [12]

Final beneficiaries of this work are considered to be the citizens and businesses. The proposed services will be userfriendly and time effective. The time taken to process their requests will be reduced to a minimum because of the time saved by the platform in the verification and the integration. Furthermore, citizens will not have to stand in very long queues as it is the case now before the employee who is surrounded by hundreds of applicants while not able to assist them.

The overall objective of this research is to "improve our understanding of the design and provisioning of integrated public electronic services which help us create meaningful and rewarding public electronic services that meet citizens and businesses needs for the case of Egypt". To meet this objective, we need to achieve the following sub-objectives:

- Improve the ways public electronic services are defined and formulated to suit the Egyptian context.

- Improve the ways public electronic services are designed and delivered to citizens and businesses.

\section{THE PROPOSED FRAMEWORK}

As discussed earlier, in this work we would like to improve the public processes and services offered by the government of Egypt. In order to do this, we will first have to understand the limitations and define ways of improvement. The proposed electronic services framework will address a number of aspects as shown in the following subsections.

\subsection{Electronic Services Process Model}

In this research, we would like to define electronic services process models which will be used to describe services process activities offered by public organisations and that meet the Egyptian context and citizen needs.

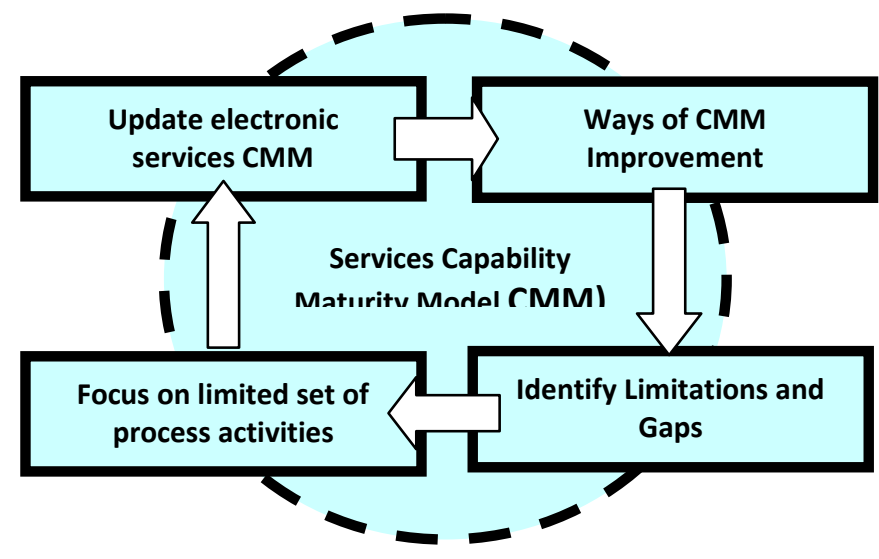

Figure 1 Service Process Improvement Cycle

The proposed process model should be able to evolve in order to accommodate new demands or requirements of the Egyptian society. We will review current offered services maturity levels and the way they are represented. In order to assess the capability maturity of these services, we need to define a model for that. There have been some efforts in the literature on capability maturity model for eGovernment [1316]. In this work, we will develop our own model that meets the Egyptian context. In parallel to that, we will investigate the different available techniques to model public electronic services in a way that makes them self-contained, technology independent and continuously adapting to changes.

As you can see in Figure 1, the process improvement will follow a cycle or in other words, is an iterative process. By determining current services maturity and identifying the main issues that are most critical to current eGovernment quality and process improvement, focusing on a limited set of activities and working aggressively to achieve them, we can steadily improve our electronic services process model and enable continuous and lasting developments.

\subsection{Electronic Services Provisioning \& Delivery}

The one-stop-shop concept is useful in bringing all services in one location which makes it beneficial from the customer point of view. However, there are a number of challenges that limit the wide usage of this approach. First of all, services are offered as it is and not really user-friendly, nor adapted to the citizen needs. Some citizens might be eligible to ask for a certain service but for others this might not be the case. Citizens from all over the country will have to visit one portal page and download PDF documents at the same time. The population of Egypt is approximately 80 millions. Assuming an average of $20 \%$ of the population to have digital skills and the capabilities to use the governmental portal and assuming every citizen will need to hit the portal once per month. Then, at least 533333 citizens will have to be support per day. This makes it quite complex to manage and the effort to improve the performance of such a website can be huge and pricy. Additionally, the one single point of entrance to the public services, in the way it is currently implemented, represents a single point of failure. If the site is down, then the whole population will not able to get served.

In this research we enunciate the need for a client-centred delivery approach that meets the complexities and needs associated with the Egyptian context. According to [7], businesses and citizens require more client-centred ways of public electronic services delivery and that with the growing complexity of the society, public organizations need to adapt to this demand. The proposed electronic services delivery model should provide the necessary guidance on ways for moving from the current state to the to-be one. Additionally it should provide ways of developing and maintaining the proposed electronic services to allow for smooth evolution as a response to new demands.

\subsection{Electronic Services Platform Architecture}

When designing the solution platform for our proposed public electronic services framework, specifying a proper architecture to provide a basis for implementation is of crucial importance.

The standard ANSI/IEEE 1471-2000 that gives recommended practices for describing the architecture of software-intensive systems defines architecture as the fundamental organization of a system, embodied in its components, their relationships and the environment, and the principles governing its design and evolution [17]. Similarly, in the Rational Unified Process [18], an architecture is the set of significant decisions about the organization of a software system, the selection of the structural elements and their interfaces by which the system is composed, together with their behaviour as specified in the 
collaborations among those elements, the composition of these structural and behavioural elements into progressively larger subsystems, and the architectural style that guides this organization, these elements and their interfaces, their collaborations and their composition [19].

Therefore, for the purpose of designing architecture, the main components of the solutions should be identified and specified. The Rational Unified Process defines a component as a non-trivial, nearly independent, and replaceable part of a system solution that fulfils a clear function in the context of a well-defined architecture [19]. A component interface is an essential element of any component since it is often the only way via which the consumer of the component knows the function of the component. In UML, an interface is defined as a named collection of operations that are used to specify a service of the component. The interface provides an explicit separation between the outside and the inside of the component, answering the question what: What useful services are provided by the particular component to the context of its existence? But not the question how: How are these services actually realized? A precisely defined component interface allows the component services to be used without knowing how they are actually realized. A component interior is hidden and not important for its environment as long as the component provides services and follows constraints defined by its contractual interface.

In defining and creating the different architecture component functionalities, their description and specification, we will follow the UML 2.0 standard specification as a modelling method. This version of the UML improves significantly the ability to represent components as, not only implementation level artefacts, but also as design-level concepts that, together with classes, represent the main mechanisms used to build a logical system architecture [21].

As mentioned earlier we will adopt service-oriented architecture principles in building our electronic services platform. During the last years, we have witnessed the further evolution of the Internet in the form of Web services [22]. Web services have been introduced as a promising way to integrate information systems effectively inside and across the enterprises. They are defined as self-contained and selfdescribing business-driven functional units that can be plugged-in or invoked across the Internet to provide flexible enterprise application integration within the Service-Oriented Architecture (SOA) [23].

Using the advanced Web service technologies such as XML (eXtensible Mark-up Language), WSDL (Web Service Description Language), SOAP (Simple Object Access Protocol), and UDDI (Universal Description, Discovery and Integration), the Internet, used to represent a repository of various kinds of information, has now evolved into a provider of a variety of business services and applications [24]. In this manner, Web services technology and SOA have increasingly become a strategic technology choice based on which organisations are able to deliver their strategic services.

The basic elements of the high-level architecture of the proposed platform are shown in Figure 2. The high-level architecture consists of the eGovernmental portals where every municipality or governorate is reached via a separate portal. The service providers (SP) make the service available and advertise it on the shared electronic services platform. The service consumers (citizens and businesses) find the service that matches their needs in a service repository using what is called as service contracts published at the intermediate platform. The service consumer and the service provider then interact in terms of providing/using the service. It is important to note that the communication between a service provider, a service consumer and a service broker is performed using the same set of interoperable, technology independent standards for communication, such as XML, SOAP and WSDL.

Service Consumers (Citizens, businesses)

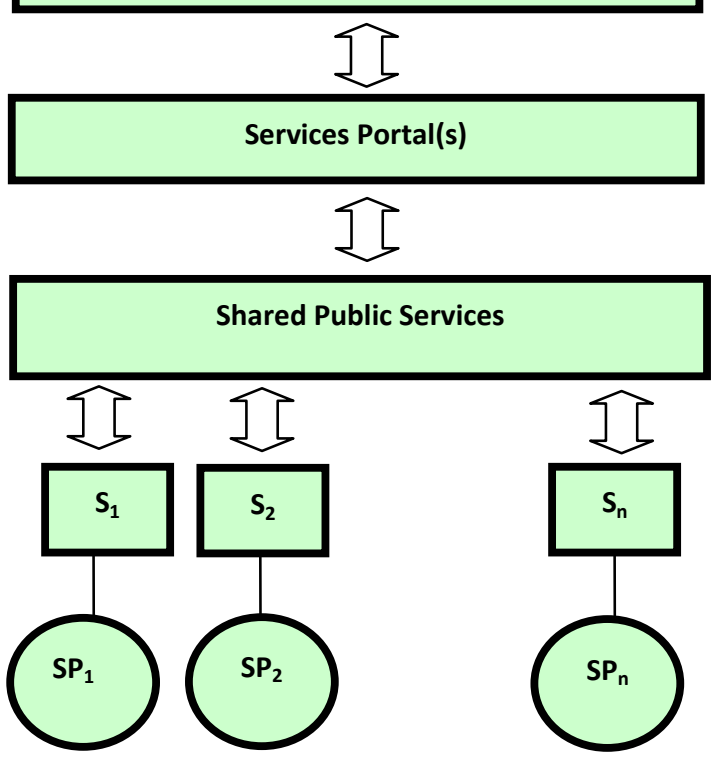

Figure 2 Services Platform High-level Architecture

The service in the form of a Web service represents a contractual agreement between provider and consumer. Beside common interface that defines operation signatures, the service also has attributes of its own such as service level agreement, policies, dependencies, security rules, privacy constraints, etc. All these properties of Web services become increasingly important when services are chained in a cascade or organized and orchestrated in a more complex way to provide a higher-level value. In this case, we potentially have more participants in the collaboration to provide a more valuable public service. Therefore, one of the main challenges for this work is placing our framework of public electronic services into a fully service-oriented environment.

\section{RELATED WORK}

E-Government encompasses a wide range of branches and sub-areas, for example the dissemination of information, services to individual citizens and businesses and participatory democracy [6]. In the last decade, we have noticed a quite intensive and growing interest in research on public electronic services in the world, especially in Europe. A lot of national projects have already started aiming at studying the design of public services and their delivery methods such as those in [6, 7, 25-27]. Lofstedt [6] argues that there are quite a number of projects on public services in Sweden that represent developments ongoing for local governmental municipalities. In the Netherlands, the BDossier concept was needed to help different organisations in the Dutch public sector to share processes and citizens personal data in order to offer better services to citizens and businesses [25]. 
Not all these efforts have managed to deliver client-centred services. For example, research results obtained by a recent study on the state of client-centred public electronic services in the Netherlands indicated that there is not yet significant differentiation among the needs of clients taken by public organisations while offering services [7]. However, the BDossier may represent one of the earliest achievements in the Netherlands in this area as a shared public electronic services framework that is more centred to people living in the Netherlands [25].

As we may have noticed, most research on e-government has focused on national needs rather than on the international context. We believe that there is still a need for the development of more research frameworks that can be used on an international context. These frameworks can act as best practices so that, developing-countries struggling to deliver client-centred public services to their citizens can benefit from the developments made in this area and shorten the time it takes to deliver useful services to their people.

\section{DISCUSSIONS AND CONCLUSIONS}

In this paper we introduced our high-level view of a shared public electronic services framework for integrating process workflows of governorates for the case of Egypt. We discussed the main components of the framework and argued for the need for developments on three levels of the proposed electronic services framework; process modelling, electronic services provisioning and delivery, and last and not least the platform architecture. Additionally we discussed how this work can be positioned among related work. There are currently two possible next steps which are parallel to each other. The first would be to focus on developing a capability maturity model for public electronic services and make use of that in our investigations to improve current public electronic services processes in Egypt and propose new ones. In order to do that, we need to analyze the different factors that characterise the Egyptian Context. Additionally, investigation is needed of the current processes and offered services. The second step is to investigate ways to deliver client-centred electronic services. Moreover, a model is needed to define the different criteria or attributes that contribute to the useful provisioning of public electronic services.

\section{REFERENCES}

[1] Gronlund, I. and T. Horan, Introducing e-Gov: History, Definitions, and Issues. Communications of the AIS, 2005. 15(39): p. 713-729.

[2] Gronlund, I. State of the art in e-Gov research: a survey. in the proceedings of the Third International Conference on Electronic Government (EGOV 2004). 2004.

[3] Scholl, H.J.J. Introduction to the Electronic Government Cluster of Minitracks. in the proceedings of the 37th Hawaii International Conference on System Science. 2004. Hawaii: IEEE.

[4] Bruecher, H., R. Klischewski, and H.J.J. Scholl. Mini Track: 'e-Government Services' (Cluster: eGovernment). in the proceedings of the 37th Hawaii International Conference on System Science. 2004. Hawaii: IEEE.

[5] Bhatnagar, S., E-Government: From Vision to Implementation: A Practical Guide with Case Studies. 2004, Thousand Oaks, London: Sage: New Delhi.

[6] Lofstedt, U., Public E-Services Research: A Critical Analysis of Current Research in Sweden. International
Journal of Public Information Systems, 2007. 2: p. 101112.

[7] Jansen, J., et al. The State of Client-Centered Public Service Delivery in the Netherlands. in the proceedings of the Eighth International Conference on Electronic Government (EGOV09). 2009: Springer-Verlag.

[8] EDEM, eServices Delivery Excellence Model. 2009, Dubai eGovernment Department: Dubai.

[9] Wimmer, M.A. eGovernment, DEMO-net and eParticipation research challenges, opportunities and prospects. in DEMO-net eGov PhD Colloquium. 2006. Krakow.

[10] Gebba, T.R. and M.R. Zakaria, E-Government in Egypt: An Analysis of Practices and Challenges. International Journal of Technology and Management, 2012. 1(1): p. $11-25$.

[11] EGSP, Egypt's Government Services Portal, http://www.egypt.gov.eg. Last visited on 13 May. 2014.

[12] TOGAF, The Open Group Architecture Framework, www.opengroup.org/togaf/: Last visited on 13 May. 2014.

[13] Iribarren, M., et al. Capability Maturity Framework for eGovernment: A Multi-dimensional Model and Assessing Tool. in the proceedings of the Seventh Conference on EGovernment (EGOV2008). 2008. Turin, Italy: SpringerVerlag Berlin Heidelberg.

[14] Davison, R.M., C. Wagner, and L.C.K. Ma, From government to e-government: a transition model. Information Technology \& People, 2005. 18(3): p. 280299.

[15] Grant, G. and D.C. Carleton, Developing a Generic Framework for E-Government, in Advanced Topics in Global Information Management, M.G. Hunter and F.B. Tan, Editors. 2006, Idea Publish. p. 72-99.

[16] Kaurahalme, O.-P., A. Syvajarvi, and J. Stenvall. From e-Government to Public Information Management: The Maturity and Future of Information Management in Local Governments. in European Group of Public Administration Annual Conference. 2011. Bucharest.

[17] ANSI, ANSI/IEEE 1471-2000 Recommended Practice for Architectural Descirption of Software-Intensive Systems. 2000.

[18] Krutchen, P., The Rational Unified Process: An Introduction. Third edition ed. 2003: Addison Wesley.

[19] Kruchten, P., The Rational Unified Process: An Introduction. Third edition. ed. 2003: Addison Wesley.

[20] Stojanovic, Z., A method for component based and service oriented software systems engineering, in Faculty of Technology, Policy and Management. 2005, Delft University of Technology: Delft. p. 257.

[21] OMG-UML2, Unified Modeling Language version 2.0. 2004.

[22] Kaye, D., Loosely Coupled: The Missing Pieces of Web Services. 1st edition ed. 2003: Rds Associates.

[23] Kaye, d., Loosely Coupled: The Missing Pieces of Web Services. 2003: Rds Associates. 
[24] Newcomer, E., Understanding Web services: XML, WSDL, SOAP and UDDI. 2002: Addison-Wesley.

[25] Lankhorst, M.M., et al., B-dossier architectuur. 2006, Telematica Institute.

[26] van Deursen, A., J. van Dijk, and W. Ebbers. Why Egovernment Usage Lags Behind: Explaining the Gap between Potential and Actual Usage of electronic Public Services in the Netherlands. in the proceedings of the
Fifth International Conference on Electronic Government (EGOV 2006). 2006. Krakow, Poland: Lecture Notes in Computer Science Springer.

[27] van Velsen, L., et al., Engineering User Requirements for e-Government Services: A Dutch Case Study Electronic Government, M. Wimmer, H. Scholl, and E. Ferro, Editors. 2008, Springer Berlin / Heidelberg. p. 243-254. 